\title{
Biocontrol potential of entomopathogenic fungi Nomuraea rileyi (f.) Samson against major groundnut defoliator Spodoptera litura (fab.) Lepidoptera; Noctuidae
}

\begin{abstract}
Biopesticides based on bacteria, viruses, entomopathogenic fungi and nematodes are often-considerable scope as plant protection agents against several insects. Use of entomopathogenic fungi as biological control agents for insect species has increased the global attention during the last few decades in the present study, biocontrol potential of entomopathogenic fungi Nomuraea rileyi (F.) Samson against groundnut defoliator Spodoptera litura (Fab.) (lepidoptera;Noctuidae) was investigated. Nomuraea rileyi SSK 07 isolate was isolated from local groundnut field soil adopting soil dilution method and the isolate was identified based on the cultural and morphological characteristics. Effect of N.rileyi on the cumulative larval mortality, lethal concentration 50(LC50), lethal time 50 (LT50), total larval and pupal period, pupal, adult emergence and adult longevity were studied. All the life stages of S.litura were susceptible to N.rileyi. In general, the concentration, duration and life stage dependent mortality could be observed. The LC50 and LT50 values were increased as the larvae grew older. As the instars advanced, a decrease in mortality and an increase in time for the mortality were recorded. Distinct effect on the development revealed short larval and pupal period. Adult emergence and adult longevity was highly influenced.
\end{abstract}

Keywords: spodoptera litura, nomuraea Rileyi, developmental period; mortality; LT50; LC50
Volume 2 Issue 5 - 2015

\section{S Karthick Raja Namasivayam, Arvind Bharani RS}

Department of Biotechnology, Sathyabama University, India

Correspondence: S Karthick Raja Namasivayam Department of Biotechnology, Sathyabama University, Chennai, Tamil Nadu, India, Tel 9 I-44-2450 I 644, Fax 44-245 I 2344,

Email biologiask@gmail.com

Received: April 02, 2015 | Published: September 08, 2015

\section{Introduction}

Groundnut (Arachis hypogaea, L.) (Fam: Leguminaceae) is an important oil seed crop in India. It occupies 8.6 million hectares, of which $85 \%$ is rainfed and $15 \%$ is irrigated. The edible oil economy of the country primarily depends upon the groundnut production. ${ }^{1}$ Insect pests are the major constraints in groundnut production. ${ }^{2}$ More than 360 species of insects and mites were reported to attack the groundnut crop in the field and the pods in storage all over the world. ${ }^{3}$ Among the various pests defoliator Spodoptera litura (Fab.) (Lepidoptera; Noctuidae) is the most serious pest causes yield loss in high magnitude throughout the world. ${ }^{4}$ S. litura is widely distributed throughout Asia and the Pacific islands.

It is an important polyphagous pest reported to feed on 112 species of plants belonging to 44 different families. Dhin have reported that one $S$. litura larva per plant at seedling stage reduced the pod yield by 25.8 percent. The early larval stages of $S$. litura feed on the leaves, flowers and pods of groundnut and reduce the production. Whereas, the late larval stages feeds on the pods in addition to the above mentioned parts. The defoliator population in groundnut ecosystem has been found to increase in number and intensity both during rainy and post rainy season, due to the destruction of natural control system, especially in fields where insecticides have been applied. ${ }^{5}$ The management of this pest using chemical insecticides is unsuccessful because of its insecticide resistance. ${ }^{6}$
Even though chemical pesticides are used to control the pest, the indiscriminate use of these chemical pesticides leads to various health hazards and insecticide resistance. ${ }^{7}$ The development of pest control measures using microorganisms' especially entomopathogens has received increasing attention in recent year. ${ }^{8-10}$ Biopesticides offer several advantages over the chemical pesticides viz. safety, targeted activity to the desired pests, effective in lower quantities thereby offering lower exposure and quick decomposition to leave no residues and allowing field re-entry immediately after application and amenability to use in rotation with chemical pesticides as part of IPM programs.

Hence research interest in augmentation and application of biopesticides has also been growing with the ultimate objective of improving commercial production and sustainable utilization of the biopesticides. In the last decade, extensive and systematic research has enhanced the effectiveness of biopesticides while the techniques for their mass production, storage, transport and application have vastly improved. ${ }^{4,10}$ Usage of entomopathogenic fungi as biological control agents of insect pests has been increasing during the last few decades. More than 750 species of fungi mostly deuteromycetes and entomophthorales are pathogenic to insects. ${ }^{11,12}$ Species that have been most intensively investigated as mycoinsecticides in the crop pest control includes Beauveria bassiana, B. brongniartrii, Metarhizium anisopliae, Nomuraea rileyi, Paecilomyces fumosoroseus, P. farinosus, Entomophthora sp, Fusarium sp, Aspergillus sp. ${ }^{\mathrm{s} E n t o m o p a t h o g e n i c ~ f u n g i ~ a r e ~ a s s o c i a t e d ~ w i t h ~ i n s e c t s ~ l i v i n g ~ i n ~}$ 
diverse habitats such as freshwater, soil and aerial location. They are very specific to insects and do not infect host plants. Among the different fungi, Nomuraea rileyi is a cosmopolitan species infecting many noctuids such as Helicoverpa armigera, Spodoptera litura, Tricoplusiani, Anticarsia gammatalis, Pseudoplusia includes and has a potential for development into mycoinsecticide and occurs in soils of various agro ecosystem. The present study undertaken to evaluate the bioefficacy of Nomuraea rileyi (F.) Samson on major groundnut defoliator Spodoptera litura (Fab.) (Lepidoptera; Noctuidae) under laboratory condition.

\section{Material and methods}

\section{Soil sampling}

Entomopathogenic fungi were isolated from the soil sample obtained from groundnut field, Chengalpet, Kanchipuram district, Tamil Nadu and processed for the isolation of fungi. Approximately $2 \mathrm{~kg}$ of soil was collected from four points a few meters apart by digging to a depth of $10-15 \mathrm{~cm}$ with a small spade. The soil samples were put in plastic bags and taken to the laboratory and stored at $25^{\circ} \mathrm{C}$. For processing, the soil was thoroughly mixed and passed through a $0.4 \mathrm{~mm}$ mesh sieve to break or separate any coarse lumps of soil or litter. Before microbial analysis, soil aggregates were broken by hands, trays with soil were kept open until moisture was at equilibrium. ${ }^{13}$ Soil texture $\mathrm{pH}$ electrical conductivity organic matter nitrate, phosphorous, potassium, calcium, magnesium sulphur, sodium, zinc, iron, copper were determined for all soil collected. These measurements were determined in national agro foundation at Taramani TamilNadu, India.

\section{Isolation of N.rileyi}

$N$. rileyi SSK 7 strain was isolated from the processed soil sample by the modified method of Clark ${ }^{14}$ using CTC (Chloramphenicol Thiobenzodazole Cyclohexamine) media. The organism was identified based on the morphological and cultural characteristics adopting standard methods and the pure culture was maintained sabouraud dextrose agar slant. Fungal morphology was confirmed by lacto phenol blue staining. ${ }^{15}$

\section{Preparation of conidial suspensions}

The re-isolated conidia were sub cultured in SMYA medium. Fungal conidia were collected from 15 days old culture by scrapping off with a sterilized glass rod. A homogenous conidial suspension was prepared in sterile distilled water by adding a few drops of the wetting agent Tween $80(0.01 \%)$. The conidial concentration of the suspension was determined using an improved Neubauer hemocytometer (Germany). Serial dilutions were made from the stock solution to obtain different conidial concentration $10^{10}, 10^{9}, 10^{8}, 10^{7}, 10^{6}, 10^{5}, 10^{4}$ and $10^{3} \mathrm{spore} / \mathrm{ml}$.

\section{Laboratory bioassay on Spodoptera lituraLarva}

The egg masses and larval instars of S. litura were collected from the groundnut field in an area around Kanchipuram and Thiruvallur district, Tamil Nadu, India. Collected larvae were maintained on groundnut leaves (TMV-7 variety). Twenty larvae in each in stars separately were sprayed with eight dose viz. $1 \times 10^{10}, 1 \times 10^{9}, 1 \times$ $10^{8}, 1 \times 10^{7}, 1 \times 10^{6}, 1 \times 10^{5}, 1 \times 10^{4}$ and $1 \times 10^{3}$ spores/ml using hand sprayer. The treated larvae were introduced into the plastic container $(34 \mathrm{~mm} \times 21 \mathrm{~mm})$ provided with moist cotton swap covered with tissue paper at the bottom of the container to provide humidity.
The containers were covered with meshed lid to provide aeration to the larvae. For control category, another 20 larvae of each in star treated with distilled water only. The containers were incubated at room temperature $28 \pm 0.5^{\circ} \mathrm{C}$ in a incubator (Remi BOD incubator, Mumbai, India). Daily observation on larval mortality was recorded for a period of 4days. The dead larvae that showed mycelial growth were considered as dead due to the fungal infection. After 96hours of the conidinal treatment, all the surviving larvae from each treatment were transferred to another container of the same size for further development. The total larval and pupal durations, adult longevity and the adult emergence were recorded.

The $\mathrm{LT}_{50}$ of the dose of fungi to kill the different larval instars was assessed in hours following Blever \& Hostetter. ${ }^{16}$ $L T 50=a+e(c-b) D$

Where, $a=$ the number of hours from the initiation of the test until the reading made just before the $50 \%$ value was recorded; $b=$ the total number of larvae dead at the reading just before $50 \%$ value was reached; $\mathrm{c}=50 \%$ of the total number tested; $\mathrm{D}=$ the number of larvae dying in 24hours period during which the $50 \%$ mortality was reached and $\mathrm{e}=$ the number of hours between mortality counts. The dose mortality data were subjected to profit analysis ${ }^{17}$ for $\mathrm{LC}_{50}$.

\section{Pupa and adult}

About 300 gram of finely sieved soil was taken in $500 \mathrm{ml}$ capacity bottle and autoclaved at 15 psi pressure for 30 minutes. After the sterilization this soil was transferred in to a clean surface sterilized $500 \mathrm{ml}$ capacity plastic container $(65 \times 32 \mathrm{~mm})$ and the soil moisture was maintained by adding $5 \mathrm{ml}$ of sterilze-distilled water. Different concentrations of conidia ranged from $10^{10}$ to $10^{3}$ spore $/ \mathrm{ml}$ were added separately. Pupa of $S$. litura was placed individually. Each treatment was replicated 10 times. Another set was maintained by adding only distilled water as control. Observations on the pupal mortality and adult emergence were recorded.

\section{Statistical analysis}

The data (between concentration of the fungal spores and instars) was subjected to ANOVA using 'STATISTICA' computer statistical package.

\section{Results and discussion}

N.rileyi was isolated from the groundnut field soil adopting culture dependent method and the isolated fungi was identified based on the cultural characteristics on the CTC media which revealed brilliant green aerial mycelia and the microscopic examination of fungal spore by lactophenol cotton blue showed spherical conidia. Soil physico-chemical parameters highly influenced the natural occurrence of Nomurea rileyi. Nomurea rileyi isolated from the respective soil sample reveals high organic matter, available nitrogen and phosphorous (Table 1). This may favour the viability of the fungal spore and thus improved the natural occurrence of Nomurea rileyi.

\section{Impact of $\mathbf{N}$. rileyi on the development of $\mathbf{S}$. litura}

Biocontrol study revealed all the life stages of Spodoptera litura susceptible to the $N$. rileyi as dose dependent manner. Concentration dependent variation on mortality was observed in all the life stages (Table 2). In the case of larval development the total larval period was statistically significant at $5 \%$ level in higher concentrations when compared to the control. Larval period was not recorded in 
the $10^{10}, 10^{9}, 10^{8}$ and $10^{7}$ spores $/ \mathrm{ml} .10^{6}, 10^{5}, 10^{4}, 10^{3}$ and $10^{2}$ spores $/ \mathrm{ml}$ recorded 12.4,13.4,14.1,15.0 and 15.4days .But in control ,the total larval period was 17.1 days.

Pupal emergence was not recorded in all the tested concentration of fungal spores. Adult emergence was not recorded at the spore concentration of $10^{10}$ to $10^{4}$. The percentage of adult emergence was 12.0 and 10.0 at the spore concentration of $10^{3}$ to $10^{2}$ and the same concentration revealed 4.1 and 5.0hours of adult longevity. Effect of fungal pathogens on development of insect pests has been reported. Hafez et al., ${ }^{18}$ has studied the effect of Beauveria.bassiana on the developmental parameters of potato tuber moth Phthorimaea operculella (Seller).

\section{LT 50 and LC 50}

All the tested concentration was capable of infecting $S$. litura larvae. Among the different concentration tested, high concentrationwas found to be significant over the least concentration $(\mathrm{P}<0.05, \mathrm{P}=0.006)$. The $\mathrm{LT}_{50}$ increased as the larvae grew older as well as with the increase in the concentration of the spore used. As the instar advanced, a decrease in mortality and an increase in time

Table I Physico chemical parameters of soil samples collected from Chengalpet groundnut field

\begin{tabular}{|c|c|c|}
\hline S. No & Parameters & \\
\hline I & $\mathrm{pH}$ & 7.95 \\
\hline 2 & Electrical conductivity $(\mathrm{ms} / \mathrm{cm})$ & 0.600 \\
\hline 3 & Organic matter (\%) & 2.33 \\
\hline 4 & Nitrate nitrogen (ppm) & 24.9 \\
\hline 5 & Available phosphorous(ppm) & 237.7 \\
\hline 6 & Potassium exchangeable k(ppm) & 93 \\
\hline 7 & Calcium exchangeable (ppm) & 1932 \\
\hline 8 & Magnesium exchangeable (ppm) & 511 \\
\hline 9 & Sulphur available s as so4 ((ppm) & 49.3 \\
\hline 10 & Sodium exchangeable $\mathrm{Na}((\mathrm{ppm})$ & 302 \\
\hline 11 & Zinc available Zn (ppm) & 2.15 \\
\hline 12 & Manganese available Mn (ppm) & 4.72 \\
\hline 13 & Iron available Fe (ppm) & 1.36 \\
\hline 14 & Copper available & 1.84 \\
\hline
\end{tabular}

Table 2 N.rileyi spore concentration on larval, pupal period, adult emergence (\%) and adult longevity (in hours) of Spodoptera litura

\begin{tabular}{|c|c|c|c|c|c|}
\hline $\begin{array}{l}\text { Dosage } \\
\text { Spores/mI }\end{array}$ & Larval Period & Pupal Period & Pupal Mortality & Adult Emergence & Adult Longevity \\
\hline $10^{10}$ & - & - & 100.0 & 0.0 & - \\
\hline $10^{9}$ & - & - & 100.0 & 0.0 & - \\
\hline $10^{8}$ & - & - & 100.0 & 0.0 & - \\
\hline $10^{7}$ & - & - & 100.0 & 0.0 & - \\
\hline $10^{6}$ & $12.4 *$ & - & 100.0 & 0.0 & - \\
\hline $10^{5}$ & $13.4 *$ & - & 100.0 & 0.0 & - \\
\hline $10^{4}$ & $14.1 *$ & - & 100.0 & 0.0 & - \\
\hline $10^{3}$ & 15.0 & - & 100.0 & 12.0 & 4.1 \\
\hline $10^{2}$ & 15.4 & - & 100.0 & 10.0 & 5.0 \\
\hline Control & I7.I & $9.3 \pm 0.7$ & 0.0 & 100.0 & $96.7 \pm 0.2$ \\
\hline
\end{tabular}

*Indicates significant between control with doses at $5 \%$ level. for initial mortality were recorded. Furthermore, the first and second, third instars larvae were highly susceptible to the fungus with $10^{10}, 10^{9}$ and $10^{8}$ spores $/ \mathrm{ml}$ which recorded the total larval mortality of $100 \%$ followed by fourth $(93.4 \%)$, fifth and sixth instar larvae (86.2 and $74.3 \%$ ) at the dosage of $10^{10}, 10^{9}$ and $10^{8}$ spores $/ \mathrm{ml} \mathrm{LT}_{50}$ value of $10^{10}$ for the fourth, fifth and sixth instars was found to be $0.12,0.91$ and 1.54days (Table 3 ).

A gradual increase in LT 50 was recorded in spore concentration dose and stage of the instar. Similar observation was also recorded in remaining concentration. The results of $\mathrm{LC}_{50}$ values determined through probit analysis were presented in Table 4 . Among the various estimate of the regression based probit analyses, the chi-square test of the bioassay showed homogeneity of the test population which is a reflection of a good fit of the observed and expected response. From the Table 3 it is very clear that the $\mathrm{LC}_{50}$ values of different larval instars of $S$. litura in response to fungal pathogen showed an increased trend in the $\mathrm{LC}_{50}$ value when the age of the larva advanced. The present study clearly reveals that all the tested fungi were found infecting life stages of S.litura and distinct effect could be observed in higher spore concentration. Field study is now progress to evaluate the fungal activity in groundnut field. 
Table 3 Effect of N.rileyi on LT 50 (days) on S.litura

\begin{tabular}{|c|c|c|c|c|c|c|c|c|c|c|c|c|}
\hline \multirow[t]{2}{*}{ Dosage spores/ml } & \multicolumn{6}{|c|}{ LT 50 (Days) } & \multicolumn{6}{|c|}{ Mortality (\%) } \\
\hline & I & II & III & IV & V & $\mathrm{VI}$ & I & II & III & IV & $\mathrm{V}$ & $\mathrm{VI}$ \\
\hline $10^{10}$ & & & & 0.12 & 0.91 & 1.54 & 100 & 100 & 100 & 93.4 & 86.2 & 74.3 \\
\hline $10^{9}$ & & & & 0.13 & 0.94 & 1.57 & 100 & 100 & 100 & 89 & 82.1 & 70.1 \\
\hline $10^{8}$ & & & & 0.15 & 0.96 & 1.58 & 100 & 100 & 100 & 79.1 & 70.2 & 65.2 \\
\hline $10^{7}$ & 0.21 & 0.99 & 1.62 & 1.7 & 1.91 & 2.01 & 90.2 & 87.2 & 78 & 69 & 60.2 & 55.4 \\
\hline $10^{6}$ & 0.34 & 0.82 & 1.97 & 2.12 & 2.32 & 2.71 & 86.1 & 79 & 69 & 59.2 & 48.1 & 40.3 \\
\hline $10^{5}$ & 0.51 & 1.21 & 2.21 & 2.93 & 3.21 & 4.23 & 78.1 & 69 & 54 & 41.2 & 30.2 & 21 \\
\hline $10^{4}$ & 0.71 & 2.02 & 2.91 & 3.11 & 4.03 & 5.11 & 69.2 & 60.1 & 50 & 37.2 & 25.2 & 11.2 \\
\hline $10^{3}$ & I.II & 3.01 & 3.97 & 4.11 & 5.1 & 6.01 & 51.2 & 40.3 & 28 & 19 & 10 & 1.21 \\
\hline $10^{2}$ & 2.11 & 4.32 & 5.1 & 5.5 & 6.11 & 7.13 & 35.4 & 24 & II & 3.1 & 0 & 0 \\
\hline Control & 0 & 0 & 0 & 0 & 0 & 0 & 0 & 0 & 0 & 0 & 0 & 0 \\
\hline
\end{tabular}

Table 4 LC50 parameters of S.litura

\begin{tabular}{|c|c|c|c|c|c|c|}
\hline \multirow{2}{*}{ Instars } & \multirow{2}{*}{$\begin{array}{l}\text { regression equation } \\
(\mathrm{Y}=\mathrm{a}+\mathrm{bx})\end{array}$} & \multirow{2}{*}{$\begin{array}{l}\mathrm{LC}_{50} \\
\mu \mathrm{g} / \mathrm{ml}\end{array}$} & \multirow{2}{*}{ Variance } & \multirow{2}{*}{ chi-square value } & \multicolumn{2}{|c|}{ 95\% confidence limit } \\
\hline & & & & & Lower limit & Upper limit \\
\hline I & $-0.44+1.280 x$ & $1.67 \times 10^{2}$ & 0.4516 & 1.59 & 1.35 & 1.76 \\
\hline II & $-3.48+1.698 x$ & $1.85 \times 10^{2} \times \times 10^{2} \times 10^{2}$ & 0.5018 & 1.61 & 1.55 & 1.98 \\
\hline III & $-0.52+0.897 x$ & $1.98 \times 10^{3}$ & 0.3801 & 2.92 & 1.87 & 2.10 \\
\hline IV & $0.16+0.509$ & $2.45 \times 10^{4}$ & 1.5362 & 4.93 & 2.22 & 2.95 \\
\hline V & $0.26+0.609 x$ & $7.12 \times 10^{4}$ & 2.011 & 5.01 & 3.10 & 3.92 \\
\hline VI & $0.56+0.709$ & $2.12 \times 10^{5}$ & 3.0 .213 & 6.12 & 3.90 & 4.34 \\
\hline
\end{tabular}

\section{Acknowledgements}

None.

\section{Conflict of interest}

The author declares no conflict of interest.

\section{References}

1. Brar K, Dhiruga K, Kaul N. The influence of sowing and harvesting date of the yield and yield attributes of four groundnut genotype planted during summer. Indian J Environ Ecopl. 2014;2(1):185-188.

2. Sahayaraj K, Martin P, Delma J. Biological control potential of aphipadophagous reduvid predator Rhynocoris marginatus (Fab.) Entomol. Crusia. 2005;7:43-51.

3. Stalker H, Campbell W. Resistance of wild species of peanut in insect campus. Peanut Sci. 1993;10:30-33.

4. Ghazal SA, Beranan, Houssein BA. Effect of actinomycetes strain on biological aspects of Spodoptera litura. Abstracts 57th International Symposium on Crop Protection, Belgium; 2005.

5. Manjula K, Arjuna RP, Nagalingam B. Record of Nomuraea rileyi (Farlow) Samson on Helicoverpa armigera Hubner in kharif Groundnut. Indian J Plant Protection. 2004;32:125.
6. Kennedy JS, Banu BS, Rabindra RJ. Entomopathogenic Fungi for the Management of Diamond Block Moth Plutella xylostella on cauliflower. In: Ignachimuthu S, et al. editors. Micorbials in Insect Pest Management. New Delhi: Oxford and IBH Publishing Co Pvt Ltd; 2001. p. 32-35.

7. Sharma . Biocontrol management of pest in organic forming. Agrobios newsletter. 2004;2:12-15.

8. Enkerli J, Widmer F, Keller S. Long term field persistence of Beauveria brongniartii strains applied as biocontrol agents European cockchafer larvae in Switzerland. Biological Control. 2004;29(1):115-123.

9. Sahayaraj K, Namasivayam SKR. Mass production of entomopathogenic fungi using agricultural products and byproducts. African Journal of Biotechnology. 2008;7(12):1907-1910.

10. Sahayaraj K, Namasivayam SKR. Field evaluation of three Entomopathogenic fungi on groundnut pests. Tropicultura. 2011;29(3):143-147.

11. Mccoy C, Sarnsonr R, Bouscies D. Inhomogeneous fungi. In: Ignoffa CM editor. SCRC press, Boca Raton: CRC handbook of natural pesticides; 1988. p. 1475-1481.

12. Padmaja V. Role of entomopathogenic fungi in insect pest management In: Ignachimuthu SJ, et al. editors. Green pesticides for integrated management. New Delhi: Narosa publishing house; 2005. p. 324. 
13. Asensio L, Carbonell T, Jimenez L, et al. Enntomopathogenic fungi in soils from Alicants province. Spanish Journal of Agriculture Research. 2003;1(3):37-45.

14. Clark M. Microorganisms standard isolation techniques. London: Academic Press; 1997. p. 271-275.

15. Humber R. Fungi- identification. In: Lacey LA editor. Manuals of techniques in insect pathology Chapter V (1). Academic press; 1997. p. $153-185$.
16. Blever A, Hostetter B. Activity of the nuclear polyhedrosis virus of the cabbage looper evaluated at programmed temperature region. Journal of invertebrate Pathology. 1971;18:81-84.

17. Finney DJ. Probit analysis. London: Cambridge University Press; 1971. p. 333-334

18. Hafez M, Zaki FN, Mours A, et al. Biological effects of the entomopathogenic fungus Beauveria bassiana on the potato tuber moth. $J$ Islamic Academy Sci. 1994;7(4):211-214. 